\title{
The Development of Abnormal Axon Trajectories after Rotation of One Eye in Xenopus
}

\author{
Yujin Guo and Susan B. Udin \\ Department of Physiology and Biophysics, State University of New York, Buffalo, New York 14214
}

The targeting of isthmotectal axons in the Xenopus binocular pathway is guided by both activity-dependent cues and activity-independent cues. Abnormal visual activity induced by unilateral eye rotation overrides activity-independent cues and causes isthmotectal axons to arborize at new locations during a critical period of development that ends $\sim 3$ months postmetamorphosis (PM). Horseradish peroxidase staining of isthmotectal axons reveals that they normally run rostrocaudally in the tectum; in contrast, those axons in animals with early eye rotation have circuitous trajectories. In this paper, by studying the trajectories and branching patterns of isthmotectal axons at different times after eye rotation, we aimed to investigate when and how activity cues determine the projection pattern of isthmotectal axons. As suggested by electrophysiological recording, isthmotectal axons initially grow normally and make arbors according to activity-independent cues despite the presence of abnormal visual input. Our findings demonstrate that the development of abnormal trajectories starts by 2 weeks PM in response to eye rotation and is a protracted process. It begins in the tectal regions in which the initial connections of isthmotectal axons are first formed according to activity-independent cues. At transitional stages ( 5 and 10 weeks), axons with arbors at two different locations are observed, with locations corresponding to the old and new termination sites, respectively. Later, at 10 weeks of age, the fainter horseradish peroxidase staining in arbors at old termination sites suggests that the older arbors are undergoing withdrawal.

Key words: optic tectum; Xenopus; activity-dependent synaptic modification; unilateral eye rotation; axon trajectories; arbors; development; nucleus isthmi
The formation of precise neuronal connections depends on activity-independent (chemoaffinity) cues and activity-dependent cues. During normal development, endogenous activityindependent cues enable axons carrying sensory inputs to form crude topographic maps (Sperry, 1963; Udin and Fawcett, 1988; Goodman and Shatz, 1993; O'Leary and Wilkinson, 1999). The further refinement of these maps requires patterned sensory activity (Schmidt and Edwards, 1983; Cline and ConstantinePaton, 1989; Scherer and Udin, 1989). The arborizations of afferent axons can be modified by activity (Udin, 1983; Antonini and Stryker, 1993b; Schmidt and Buzzard, 1993; Katz and Shatz, 1996). Normally, chemoaffinity and activity-dependent cues work in harmony, but abnormal eye position in Xenopus during development can set up a conflict whereby visual input induces axons to shift their arbors away from the sites specified by chemoaffinity markers. In this study, we examined the process of reorganization of axons in the Xenopus visual system that results from a mismatch of activity-dependent and chemoaffinity cues.

The topographic representations of the binocular visual field in Xenopus optic tectum have been studied by electrophysiological mapping (Gaze et al., 1979). The contralateral and ipsilateral maps are in spatial registration during normal development. The formation of the contralateral map begins within a few days of

Received Nov. 10, 1999; revised Feb. 16, 2000; accepted March 21, 2000.

This work was supported by United States Public Health Service Grant EY-03470 to S.B.U. We thank Drs. Simon Grant, Vicky Stirling, and Wenbiao Gan for their helpful comments on this manuscript and Dr. Diana Williams for use of Fig. $3 B$.

Correspondence should be addressed to Dr. Susan B. Udin, 313 Cary Hall, Department of Physiology, State University of New York, Buffalo, NY 14214. E-mail: sudin@buffalo.edu.

Dr. Guo's present address: Department of Psychiatry, Mount Sinai School of Medicine, New York, NY 10029.

Copyright (C) 2000 Society for Neuroscience $0270-6474 / 00 / 204189-09 \$ 15.00 / 0$ fertilization and is independent of visual experience (Gaze et al., 1979; Keating et al., 1986). In contrast, the ipsilateral map develops much later, at the end of metamorphosis. An initially coarse ipsilateral map forms regardless of the presence or absence of proper visual cues (Grant and Keating, 1989b). However, the maintenance and refinement of the ipsilateral map is mediated by correlated activity between the two eyes during the critical period (Keating and Feldman, 1975; Brickley et al., 1998). When one eye is surgically rotated, resulting in a rotated contralateral map, the initially normal ipsilateral map is topographically mismatched but later reorganizes and conforms to the rotated contralateral map (Fig. 1) (Udin and Keating, 1981). Electrophysiological studies show that, although the eye rotation is performed before the formation of the ipsilateral map, the first sign of modification of the ipsilateral map is not detected until $\sim 3-4$ weeks postmetamorphosis (PM) (Grant and Keating, 1992; Bandarchi et al., 1994).

The ipsilateral visual information is relayed through the nucleus isthmi (NI) (Glasser and Ingle, 1978; Gruberg and Udin, 1978). The isthmotectal projection is the plastic component in the ipsilateral pathway (Udin and Keating, 1981). In normal animals, the majority of the isthmotectal axons run in a straight rostrocaudal direction in the tectum. However, eye rotation induces isthmotectal axons to take abnormal routes (Udin, 1983). The anomalous trajectories are the anatomical basis for the rearrangement of the ipsilateral map in response to early eye rotation.

In the experiments described in this paper, we report that abnormal activity starts to affect the isthmotectal axons by 2 weeks PM. Moreover, during transitional stages when the guiding forces for isthmotectal axon arborizations are shifting from chemoaffinity cues to activity-dependent cues, some axons exhibit arbors at two locations. 


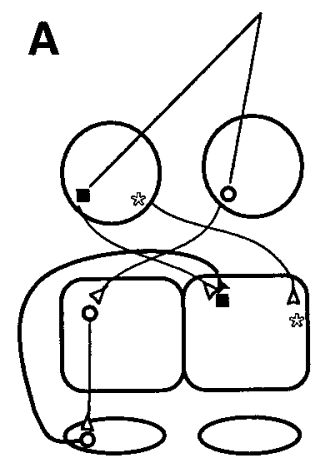

Normal

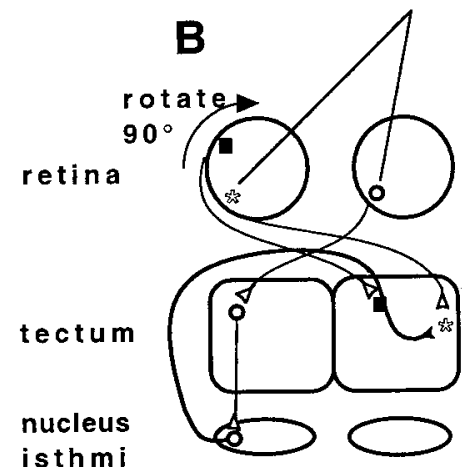

Rotated
Figure 1. A, Schematic diagram showing binocular visual input to one locus on the right tectal lobe in a normal adult Xenopus. Visual input via the left eye is relayed directly via retinotectal axons. The input from the right eye is carried indirectly via isthmotectal axons. The input at each position in the binocular field activates a single locus on the right tectum via both pathways. $B$, After the rotation of the left eye, stimulation at the same position in the visual field now activates different retinal ganglion cells in the left eye, which project to another locus on the right tectum. Therefore, isthmotectal axons must shift their connections to restore topographic registration with retinotectal axons.

\section{MATERIALS AND METHODS}

Eye rotation. Tadpoles of stage 55-58 (Nieuwkoop and Faber, 1967), bred in our laboratory, were anesthetized by immersion in 1:2000 MS-222 (3-aminobenzoic acid ethyl ester; Sigma, St. Louis, MO). All of the extraocular muscles in the left eye were cut, and the left eye was rotated $180^{\circ}$ about its axis. The eye was held at the rotated position for $30 \mathrm{sec}$ to allow the periorbital tissue to adhere. In many cases, various degrees of derotations occurred. Only animals with final rotations of $90-180^{\circ}$ were used.

Axon labeling. Horseradish peroxidase (HRP) was injected into the NI at 2 weeks, 5-6 weeks, 9-10 weeks, or $4+$ months PM. The frog was anesthetized, and the tectum was exposed. The frog was positioned with the upper jaw horizontal. Glass filament micropipettes with tip diameters of $20-40 \mu \mathrm{m}$ were filled with a mixture of $4.0 \%$ HRP (Type VI; Sigma) and $1.0 \%$ lysolecithin (Sigma). Six to 12 pressure injections were made in the left NI at 500-700 $\mu \mathrm{m}$ from the midline, 50-200 $\mu \mathrm{m}$ from the caudal tectal border, and $800-1050 \mu \mathrm{m}$ deep. The number and sites of injections varied with the size of the animal. After 3 d survival, animals were reanesthetized. The right tectal lobe was excised, flattened, fixed in $2.5 \%$ glutaraldehyde, and reacted for visualization of HRP (Udin and Fisher, 1983).

Data analysis: overall axon orientation. A method was devised to measure the orientation of isthmotectal axon trajectories using the MicroBrightField (Colchester, VT) Neurolucida system (Udin, 1983): Using a $40 \times$ objective, a pair of $50 \mu \mathrm{m}$ orthogonal lines was superimposed on the image of the isthmotectal axons being studied, with one line being oriented along the axis normally, followed by isthmotectal axons (see Fig. 3). We referred to this line as "RC" to indicate that it was parallel to the normal trajectory of the isthmotectal axons, which generally run rostrocaudally, with some deviation at the tectal edges; the other line was referred to as "ML" to indicate its mediolateral orientation. The numbers of crossings of isthmotectal axons with the ML and RC segments were counted for each field, and the value of the crossing index $[(\mathrm{ML}-\mathrm{RC}) /(\mathrm{ML}+\mathrm{RC})]$ was calculated. Perfect rostrocaudal alignment would produce a value of 1 , and completely random trajectories would yield a value of 0 . Predominance of mediolateral trajectories would produce negative values.

The number and location of HRP-labeled axons in the whole mounts varied depending on the location of the injection sites in the NI. To study the labeled axons with minimal bias, the following procedure was adopted. Under a $40 \times$ objective, a field with stained axons was chosen. Using the Neurolucida program, a $50 \mu \mathrm{m}$ grid was superimposed on the axon image and was oriented as described above. Crossings of axons with the $\mathrm{RC}$ or/and ML lines were marked. Then the stage was moved one screen frame $(100 \mu \mathrm{m})$. Unless the new field was empty or contained broken axons, crossings of axons in this field with the grid were marked as described above. Usually, the pair of orthogonal lines with the intersection closest to the center of the image was chosen. Only the crossings of the orthogonal lines with the "stem" axons were counted. If a profile branched more than five times in the image field, it was considered to be a terminal arbor and was not counted. This procedure was repeated until all the available fields had been surveyed. The outline of the tectum was then traced using a $10 \times$ objective.

The regions with labeling on the medial, rostral, and lateral borders were not used in the pooled data. The orientation of the axons on the very edge of the whole mounts was not well preserved; for the axons on the very rostral side of the tectum, it was difficult to study the changes in their trajectories because they had very short stems. The whole mounts with fewer than five axons were not used.

Data analysis: individual axon trajectories. Some HRP-labeled axons in the whole mounts were well separated from the other axons and were intact from their point of entry to tectum to the terminal arborizations. In those cases, those axons were traced from their point of entry to the end of every terminal using a $100 \times$ objective. When this was done, the outline of the tectum was traced under a $10 \times$ objective.

In some cases, the borders of the tecta in whole mounts were not clear. Some landmarks used to estimate the boundaries included the optic tract, the axons on the very medial edge and lateral edge, and the rostral border of the tecta in which the incoming isthmotectal axons changed their trajectories sharply and spread out.

\section{RESULTS}

After eye rotation, isthmotectal axons shift their terminal arbors from one location to another to reestablish topographic registration with retinotectal projections (Fig. 2). Rotations of the contralateral eyes $\left(90\right.$ and $180^{\circ}$ ) cause the topographic maps of retinotectal projections on the right tectum to rotate accordingly (Grant and Keating, 1992; Keating and Grant, 1992). To restore registration with retinotectal axons, the topographic maps of isthmotectal axons also rotate to similar degrees. As deduced from the normal map and that after $90^{\circ}$ rotation, in an animal with $90^{\circ}$ eye rotation, isthmotectal axons that used to terminate in areas $a, b, c$, and $d$ now terminate in new areas $A, B, C$, and $D$, respectively. Note that the shift is minimal in axons in area $d$, which receives inputs from the central part of the visual field.

The trajectories and arborizations of isthmotectal axons in the tectum were visualized by injecting the NI with HRP (Fig. $3 A, B$ ). In normal animals, isthmotectal axons entered the tectum from the rostral side and grew caudally, rarely changing their positions along the mediolateral axis. The great majority were parallel to one another and had a high level of order. However, eye rotation induced isthmotectal axons to take abnormal routes to reach new termination sites; many ran in medial and lateral directions, and some made U-turns. The likelihood that these axons crossed one another was large. As a result, the degree of the rearrangement of isthmotectal axons can be assessed by their lack of order.

\section{The rearrangement of isthmotectal axons in response to unilateral eye rotation starts by 2 weeks PM and continues well into 10 weeks PM}

The orderliness of the isthmotectal axons was reflected by the values of the crossing indices (Fig. 3C,D). Briefly, a pair of orthogonal lines was superimposed on the image of the isthmotectal axons at different tectal positions, with one line $(R C)$ being oriented along the axis normally, followed by isthmotectal axons, and the other line $(M L)$ running orthogonally. The numbers of crossings of isthmotectal axons with the ML and RC segments were counted for $50 \times 50 \mu \mathrm{m}$ segments, and the value of the crossing index $[(\mathrm{ML}-\mathrm{RC}) /(\mathrm{ML}+\mathrm{RC})]$ was calculated. Perfect rostrocaudal alignment would produce a value of 1 , and completely random trajectories would yield a value of 0 .

The sample included 1409 axon crossings in 33 eye-rotated 

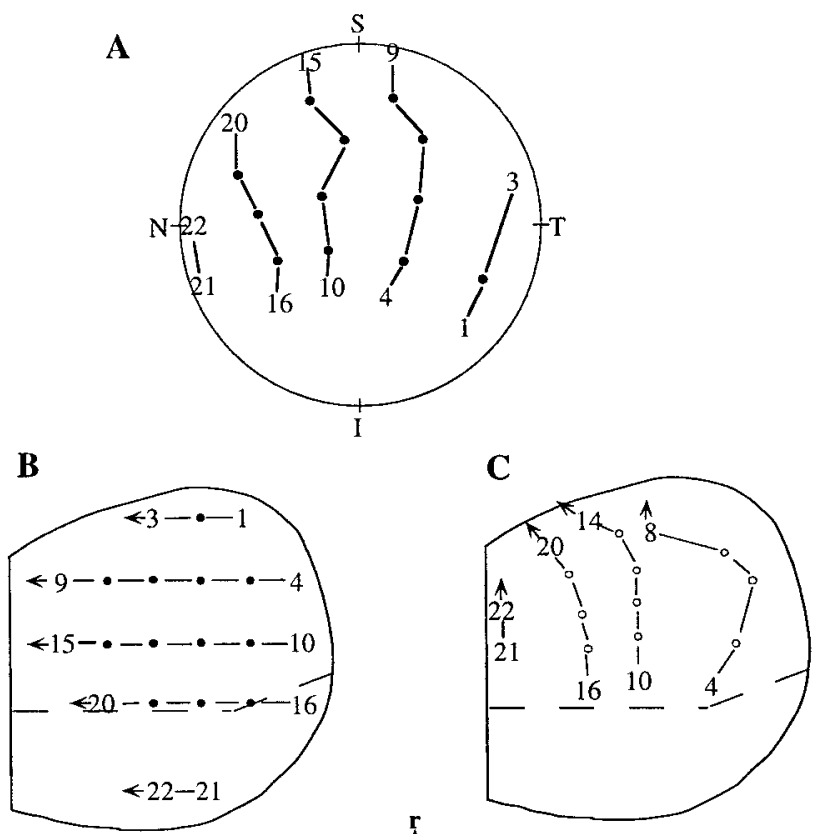

$90^{\circ}$ rotation

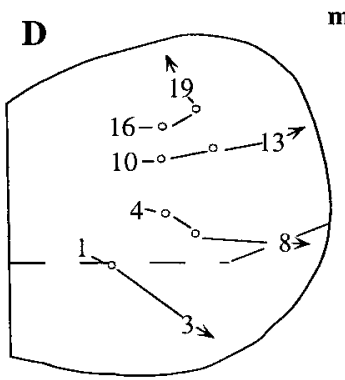

$180^{\circ}$ rotation

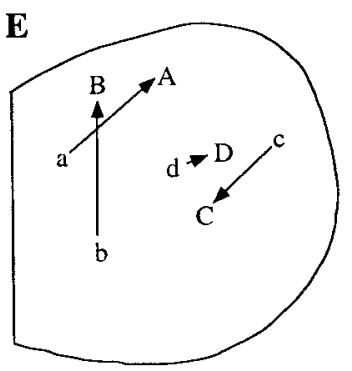

$90^{\circ}$ rotation

Figure 2. The changes in visual topography on the right tectal lobe after eye rotation in an adult Xenopus at 1 year PM. $A$, The visual field through the left eye. The topographic maps on the right tectum in animals with no eye rotation $(B), 90^{\circ}$ clockwise rotation of the left eye $(C)$, and $180^{\circ}$ rotation of the left eye $(D)$, inferred from the electrophysiological recording of retinotectal maps. Numbers and circles represent the locations of stimuli in the visual field and the sites that those stimuli activate in the tectum. For example, site 4 in the tectum in $B$ is activated by a stimulus at position 4 in the visual field. After eye rotation, the stimulus at the same position in the visual field will activate a different location in the tectum. The new location is given the same number, e.g., 4, and represented by an open circle. The isthmotectal axons that normally project to the old location of site 4 in the normal animal will project to the new location 4 after eye rotation. The dotted line represents the caudal border of isthmotectal projections in normal animals. $E$, After $90^{\circ}$ rotation, the isthmotectal axons that project to areas $a, b, c$, and $d$ in normal animals terminate in areas $A, B, C$, and $D$. Axons that project to the middle part of the tectum (area $d$ ) change their termination sites very little because they activate the part of the eye near its axis of rotation. [Adapted from Grant (1982).]

animals and 372 crossings in 31 controls. The crossing indices from all ages are charted in Figure 4. In normal animals, the crossing indices did not change significantly with age. However, there were marked differences between the eye-rotated group and the normal group. The rearrangement of isthmotectal axons in the eye rotation group started by 2 weeks PM, at which time isthmotectal axons already displayed considerable disorder. With increasing age, the degree of rearrangement became progressively larger. The development of this disorder was a gradual
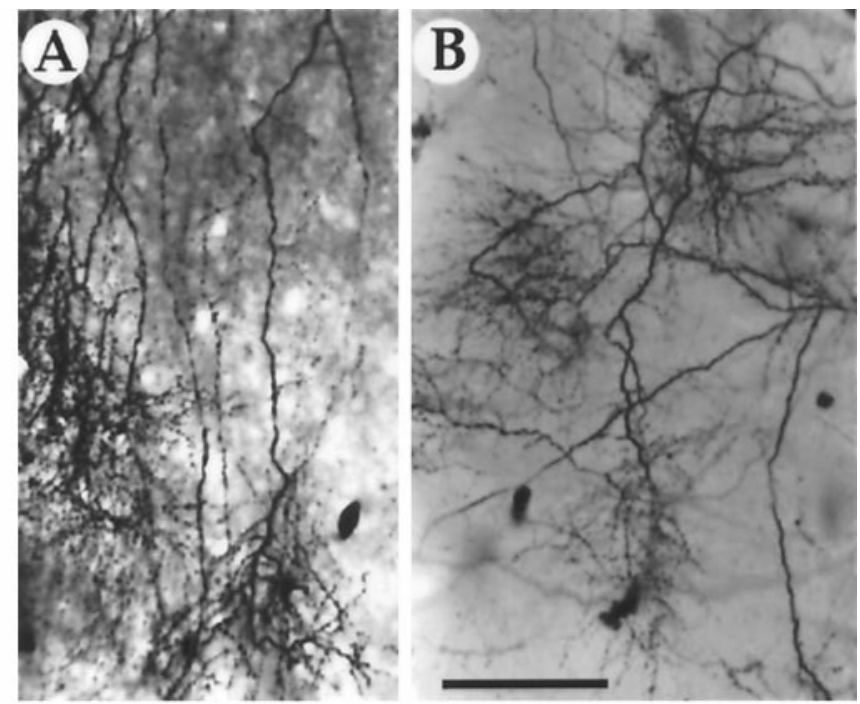

C

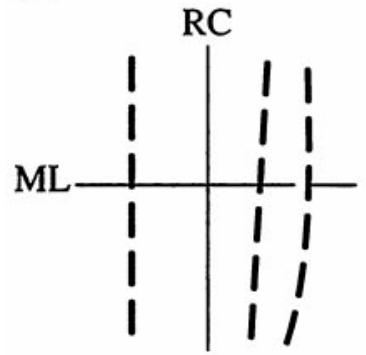

c. i. $=1$
D

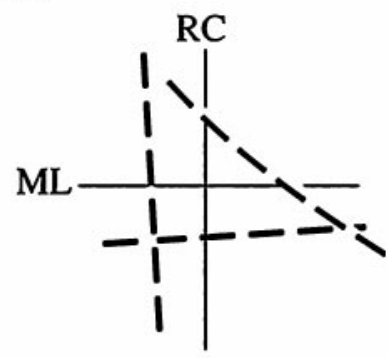

c. i. $=0$
Figure 3. $A, B$, Photomicrographs depicting HRP-stained isthmotectal axons in flat-mounted tecta in adults. $A$, Normal. In normal adults, isthmotectal axons run straight from rostral to caudal and are parallel to one another. $B$, Eye-rotated adults. Adult isthmotectal axons in eyerotated animals show a low degree of order. Scale bar, $100 \mu \mathrm{m}$. Rostral is $u p$, and medial is left. $C, D$, A schematic drawing showing the measurement of crossing index (c. i.). A pair of orthogonal lines is superimposed on the axons (dashed lines) being measured. Crossings of axons with RC and ML lines are counted.

process. Differences in crossing indices reached statistical significance when pairs of groups separated by $>7$ weeks were compared. Crossing indices in successive eye-rotation groups did not differ significantly from one another.

\section{At transitional stages, isthmotectal axons form two arbors, with one consistent with activity-independent cues and the other consistent with abnormal activity cues}

Electrophysiological studies have demonstrated that eye-rotated animals have essentially normal ipsilateral maps for the first few weeks after metamorphosis (Grant and Keating, 1992), suggesting that the isthmotectal axons initially make functional arbors in the normal locations. Ultimately, when the reorganization was complete, the isthmotectal axons arborized at different locations, and the vast majority of them (34 of 35) had only one arbor (Fig. $5 D)$. To understand how the isthmotectal axons arrive at the locations specified by eye rotation, we studied the branching patterns of isthmotectal axons at transitional stages. Our studies revealed that eye rotation induced isthmotectal axons that ini- 


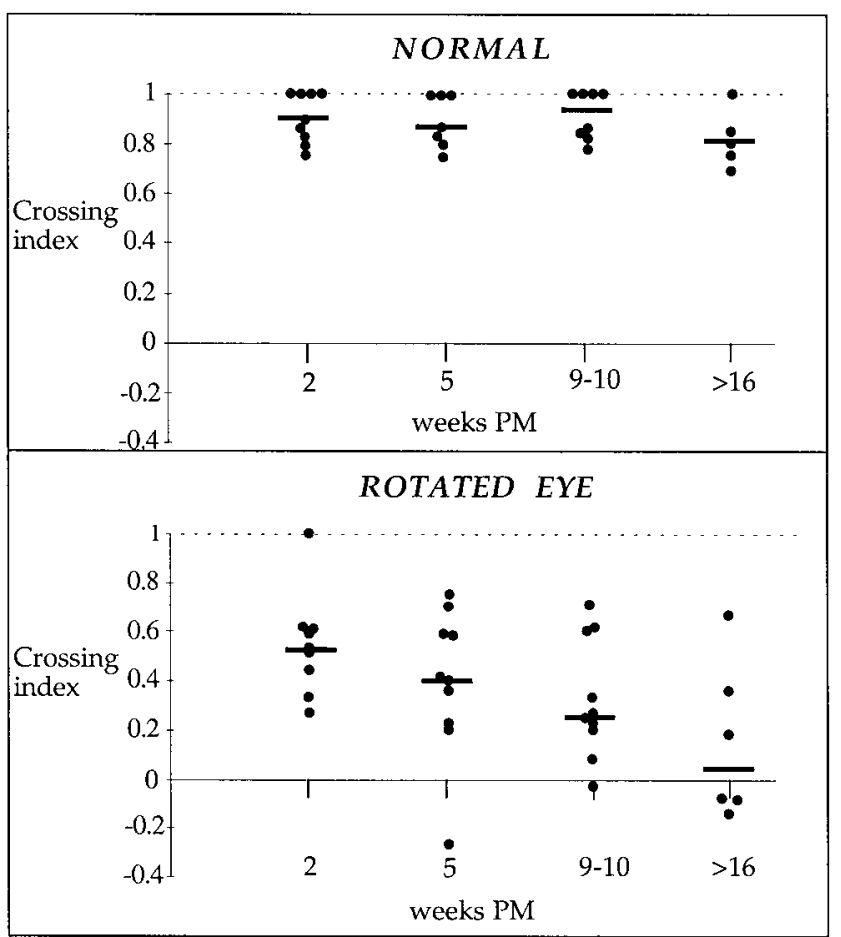

Figure 4. Analysis of isthmotectal axon trajectories. Each dot represents the total crossing index of one tectum. Bars represent the median. $A$, Crossing indices in normal animals. The isthmotectal axons in normal animals display orderly trajectories at all age groups. $B$, Crossing indices in eye-rotated animals. The isthmotectal axons in eye-rotated animals exhibit abnormal trajectories starting at 2 weeks PM, and the degree of rearrangement increases with the age of the animals. Differences in crossing indices reached statistical significance between 2 and 9-10 weeks (Mann-Whitney test, $p=0.0244$ ), 5 and $>16$ weeks (Mann-Whitney test, $p=0.0280$ ), and 2 and $>16$ weeks (Mann-Whitney test, $p=0.002$ ).

tially had one arbor to sprout new branches and form new arbors; the old arbors were subsequently withdrawn.

\section{Axons in normal animals}

Normal developing axons are shown in Figure 5. At 2 weeks PM, there coexisted mature-looking axons with arbors and immaturelooking axons with only scattered branches, indicating that not all axons were at the same developmental stages. Both types of axons tended to grow straight in a rostrocaudal direction and did not extend branches mediolaterally. At 5 and 9-10 weeks PM, axons in normal animals had single, focused arbors and straight rostrocaudal trajectories. Similar results have been reported by Udin (1989).

\section{Axons in eye-rotated animals}

Two weeks PM. In animals with a rotated eye, both maturelooking axons with arbors and immature-looking axons with only scattered branches were observed (Fig. 5A). No apparent difference was seen in immature-looking axons between eye-rotated (a3) and normal animals. In contrast, among four mature-looking axons with arbors in eye-rotated animals, three of them extended long branchlets outside their arbors, one caudally (a1) and the other two mediolaterally (a2). These patterns were not observed in normal animals.

Five weeks PM. Fourteen axons that were well separated from the neighboring axons were traced (Fig. $5 B$ ). Of these, six axons had single focused arbors. In contrast, the rest had branching patterns that were not present in normal animals; three axons extended branchlets away from their arbors (b1), and five made dense arbors at two different locations. The tecta of three of the "two-headed" axons had clearly identified borders that allowed us to identify the locations of the arbors; two had one set of arbors caudal and slightly medial to the other set of arbors (b3), and one axon made two arbors along the mediolateral axis (b2).

Nine to 10 weeks PM. Of eight clearly identified axons, three axons had normal trajectories and single arbors (Fig. 5C). The rest had abnormal appearances. Three axons had abnormal trajectories and single arbors, as observed in eye-rotated adults $(c 1)$; two axons had two sets of arbors (c2 and c3).

More than 16 weeks PM. The majority of 35 traced axons had abnormal trajectories and single arbors (Fig. 5D, $d 1, d 4$ ); one had two arbors $(d 2)$, and one had branches outside the main arbor $(d 4)$.

\section{The locations of arbors in two-headed axons}

In animals with early eye rotation, two distinct morphologies of axons in transitional stages were the extension of ectopic branches from main arbors at 2 and 5 weeks PM and the presence of axons with two separated arbors at 5 and 10 weeks PM. If the formation of two arbors is a step that leads to the final development of arbors at the location specified by the activity-dependent cues resulting from eye rotation, one would expect that the location of one arbor in each such two-headed axon would correspond to the normal termination site and the other arbor to the reorganized site.

To investigate the locations of arbors in each two-headed axon, the topographic maps of isthmotectal axons after different degrees of eye rotation were examined. All three two-headed axons in 5 week PM tecta with identifiable locations and two twoheaded axons in 10 week PM tecta had one set of arbors, corresponding to the old site and another set corresponding to the new termination site. Figure $6 A$ shows the predicted locations of new arbors in several axons after 90 or $180^{\circ}$ eye rotation. After $90^{\circ}$ rotation, axons that used to project to positions $a$ and $b$ terminated at positions $A$ and $B ; 180^{\circ}$ rotation induced axons to shift their connections from original sites $c$ and $d$ to new sites $C$ and $D$.

Examples of axons with two arbors at the predicted old and new sites are shown in Figure $6 B$. Axons 1 and 2 came from a 10 week PM animal with $90^{\circ}$ rotation; one set of their arbors was localized at original termination sites $a$ and $b$, and another set of arbors was found in the postulated new sites $A$ and $B$. Axons 3 and 4 , in 5 week PM animals with $180^{\circ}$ rotation, had arbors at putative old termination sites $c$ and $d$ and another set of arbors at probable new termination sites $C$ and $D$, respectively.

Changes in intensity of HRP staining in axons with two arbors Interestingly, in both axons from a 10-week-old animal, arbors found at the old termination were thinner and more lightly stained than the arbors at the new sites (Fig. $7 A, B$ ). On the other hand, both sets of arbors in the two-headed axons from the 5-week-old animals showed similar intensity of HRP staining (Fig. 7C). This finding suggests that, at 10 weeks PM, some isthmotectal axons were withdrawing the old arbors. Also at this age, some axons had abnormal trajectories and single arbors, indicating that these axons had already completed the process of withdrawing old arbors (Fig. $7 C$ ). In fact, among 35 isthmotectal axons in adult animals with early eye rotation (Fig. $7 D$ ), although the majority of them had abnormal trajectories and one arbor, 
A

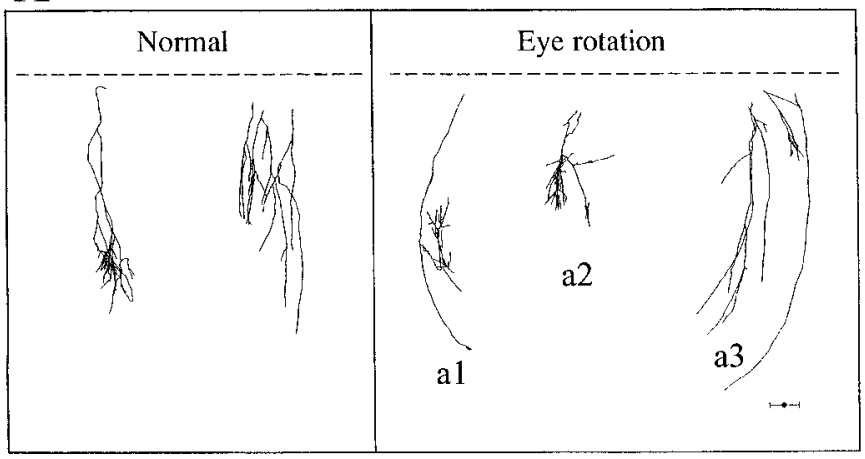

C

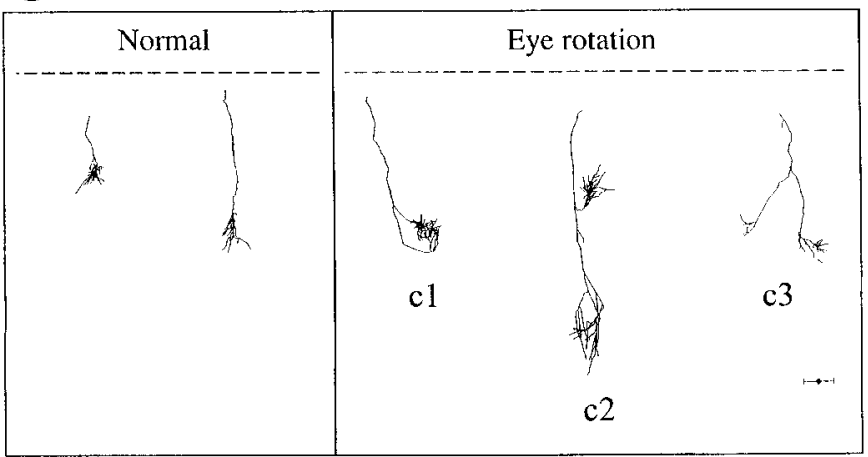

B

5 weeks PM

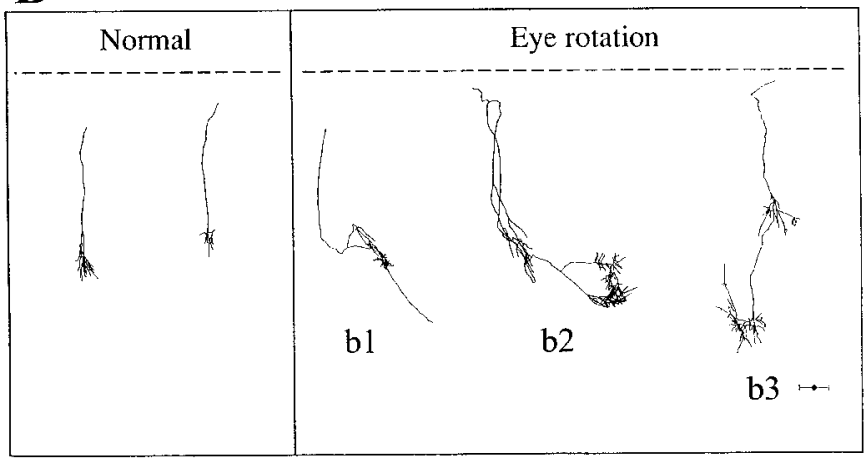

D

$>16$ weeks PM

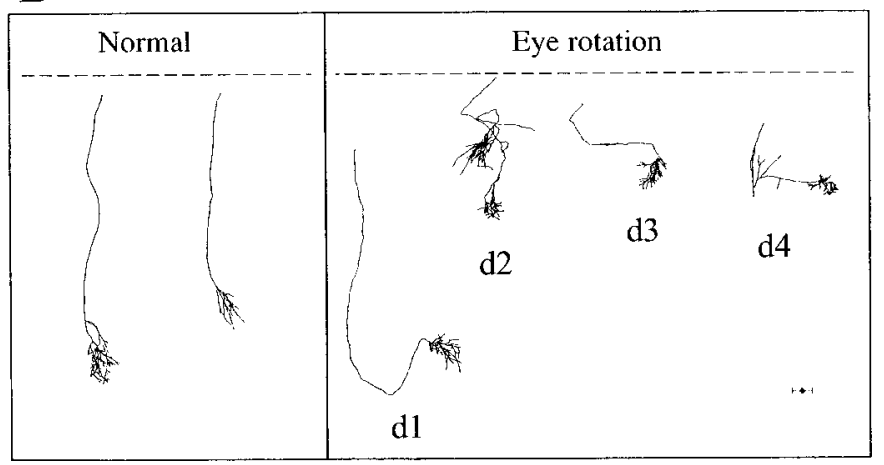

Figure 5. Tracings of HRP-stained isthmotectal axons. A, Two weeks PM. Both normal animals and eye-rotated animals at this age have some axons with dense arbors ( $a 1$ and $a 2$ ), as well as axons with scattered branches (a3). Note that the axons with dense arbors in eye-rotated animals extend branchlets outside their arbors $(a 1$ and $a 2)$. B, Five weeks PM. Each axon in normal animals has one arbor. In eye-rotated animals, some axons extend branchlets outside their arbors (b1), and others have arbors at two locations (b2 and $b 3)$. $C$, Nine to 10 weeks PM. Some axons in eye-rotated animals have two arbors ( $c 2$ and $c 3$ ), whereas others have abnormal trajectories and one arbor $(c 1)$. $D$, More than 16 weeks. In normal animals, axons each have one arbor and rostrocaudally oriented trajectories. In eye-rotated animals, the majority have circuitous trajectories and one arbor $(d 1$ and $d 3)$. The single observed case of an axon with two arbors at this age group is shown in the drawing (d2). Also shown is an axon that makes a lateral turn and retains remnant branches outside the main arbor $(d 4)$. Scale bar, $100 \mu \mathrm{m}$.

one axon had remnant branches at positions other than main arbor $(d 4)$ and another axon had two arbors, which may represent a failure of the complete withdrawal of old arbor $(d 2)$.

There could be several reasons why we observed a population of "normal-looking" axons with straight trajectories and single arbors in eye-rotated animals (data not shown). (1) The axons may not have started to change. (2) Some axons were in the middle of the tectum, corresponding to the optic axis of the rotated eye, where minimal changes are expected because new termination sites are very close to the old sites. (3) Some axons shifted connections from a rostral to a caudal location or vice versa, at the same mediolateral position (for example, see Fig. 7B, b3). (4) Not all axons responded to eye rotation.

\section{Isthmotectal axons with younger arbors are the last group of axons to undergo rearrangement}

NI cells are born over a period of 1-2 months, and most of their axons have arrived at the tectum at the time of eye rotation. However, they make only scattered branches until $\sim 1$ week before metamorphosis, when the oldest axons start to form arbors in rostromedial regions (Udin and Fisher, 1985; Udin, 1989). As development proceeds, relatively younger axons form arbors in the rostromedial region and displace older axons and their arbors to the caudolateral part of the tectum (Grant and Keating, 1986, 1989a). Because of the pattern of tectal growth (Udin and Fisher 1985), axons retain an overall rostrocaudal orientation, albeit with a small lateral bias in the lateralmost tectum. Thus, NI cells that ultimately project to the caudolateral part of the tectum are the oldest and also have the oldest arbors induced by activityindependent cues. At 2 weeks PM, we observed that some isthmotectal axons had arbors and others only had scattered branches. This result indicates that arbors induced by activityindependent cues are still forming and that isthmotectal axons are at different developmental stages at these ages.

Do all isthmotectal axons respond to eye rotation at the same time, independent of their individual stages of development? To answer this question, we investigated the distribution of the crossing indices across the tectum in different age groups. In Figure 8, the large black circles represent sites with the greatest disorder of trajectories (smallest crossing index). In the 2 week PM group, the most prominent rearrangements were found in the caudolateral part of the tectum. In the 5 week PM group, the zone of reorganization had spread medially, leaving primarily rostromedial axons still in their normal positions. In animals of 10 weeks PM, only axons within a narrow medial band still had normal trajectories. In animals older than 16 weeks, the reorganization had been completed in virtually every region. This result shows that isthmotectal axons reorganized following the order of caudolateral to rostromedial. Thus, younger axons with newly formed activity-independent arbors were the last group to be affected by eye rotation. 
A
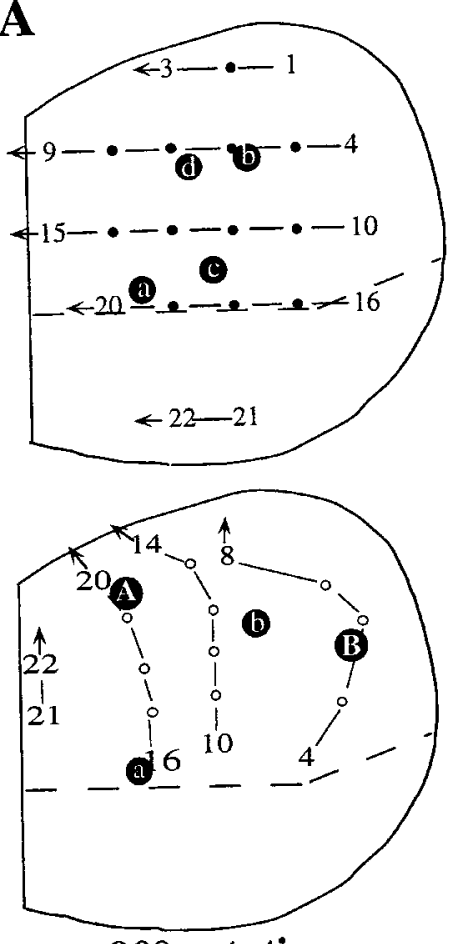

$90^{\circ}$ rotation

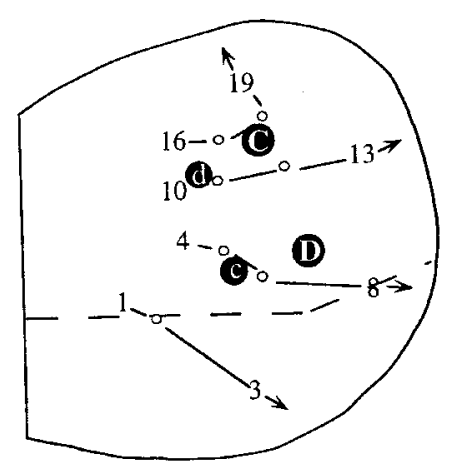

$180^{\circ}$ rotation

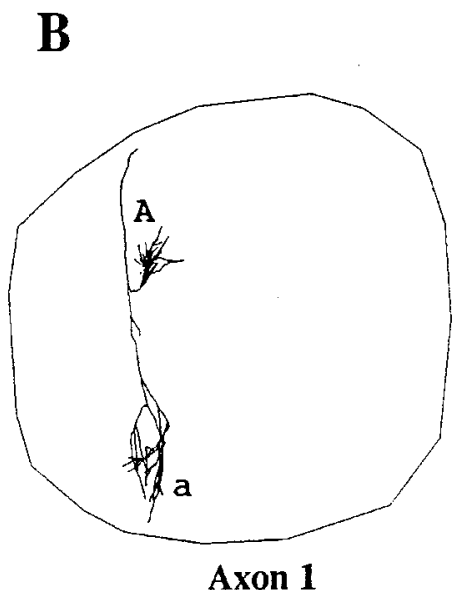

Axon 1

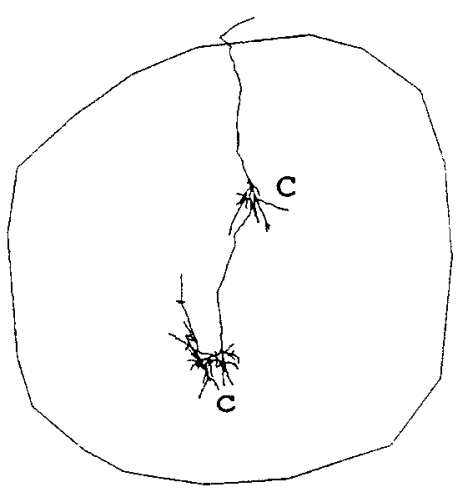

Axon 3

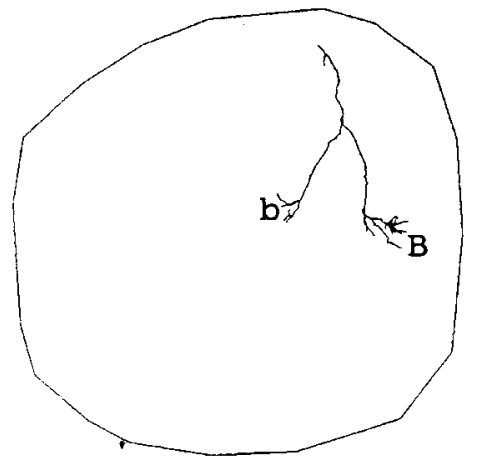

Axon 2

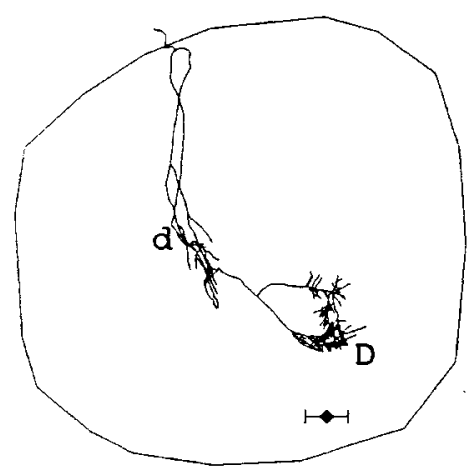

Axon 4

Figure 6. In two-headed axons, one arbor is located in the normal site, and the other is found at a site appropriate for the rotated map. $A$, Prediction of new termination sites of axons after eye rotations. The top panel shows the termination sites of four axons in normal animals, represented by $a, b, c$, and $d$. The middle panel shows the new termination sites $(A$ and $B)$ of axons $a$ and $b$ after $90^{\circ}$ eye rotation. The old termination sites are also marked. The bottom panel shows the new terminations sites $(C$ and $D)$ of axons $c$ and $d$ after $180^{\circ}$ eye rotation. The dotted line represents the caudal border of isthmotectal projections in normal animals, which also corresponds to the caudal margin of our whole mounts. $B$, Tracings of two-headed axons $1,2,3$ and 4 . Axons 1 and 2 are from animals at 10 weeks PM with $90^{\circ}$ rotation and have one set of arbors at $a$ and $b$ and the other set at $A$ and $B$, respectively. Axons 3 and 4 are from animals at 5 weeks PM with $180^{\circ}$ rotation and have one set of arbors at $c$ and $d$ and the other set at $C$ and $D$. Scale bar, $100 \mu \mathrm{m}$.

\section{DISCUSSION}

The present study demonstrates that eye rotation starts to affect isthmotectal axon trajectories by 2 weeks postmetamorphosis and that individual axons transiently sustain two distinct arborizations during the critical period. Further analysis of the locations of paired arbors shows that they represent the normal and reorganized termination sites, suggesting that abnormal visual activity can induce sprouting of new arbors and subsequent withdrawal of the old arbors.

Unilateral eye rotation at tadpole stages leads to the reorganization of the ipsilateral map (Udin and Keating, 1981). However, electrophysiological mapping methods do not reveal rotated ipsilateral maps until 3-4 weeks postmetamorphosis (Udin and Keat- ing, 1981). Thus, a normal map forms and persists for at least another month, although abnormal visual input is present throughout the whole period. By staining isthmotectal axons with HRP to characterize when and how isthmotectal axons are guided by activity cues, we could examine subtle changes in branching patterns of isthmotectal axons in response to abnormal visual activity that are difficult to detect by extracellular electrophysiological mapping (George and Marks, 1974).

Our results show that isthmotectal axons start to extend ectopic branches in the earliest age group we studied: 2 weeks PM. Thus, isthmotectal axons respond to abnormal activity before changes are detected by electrophysiological mapping because no dense arbors at rotated positions have formed yet. 

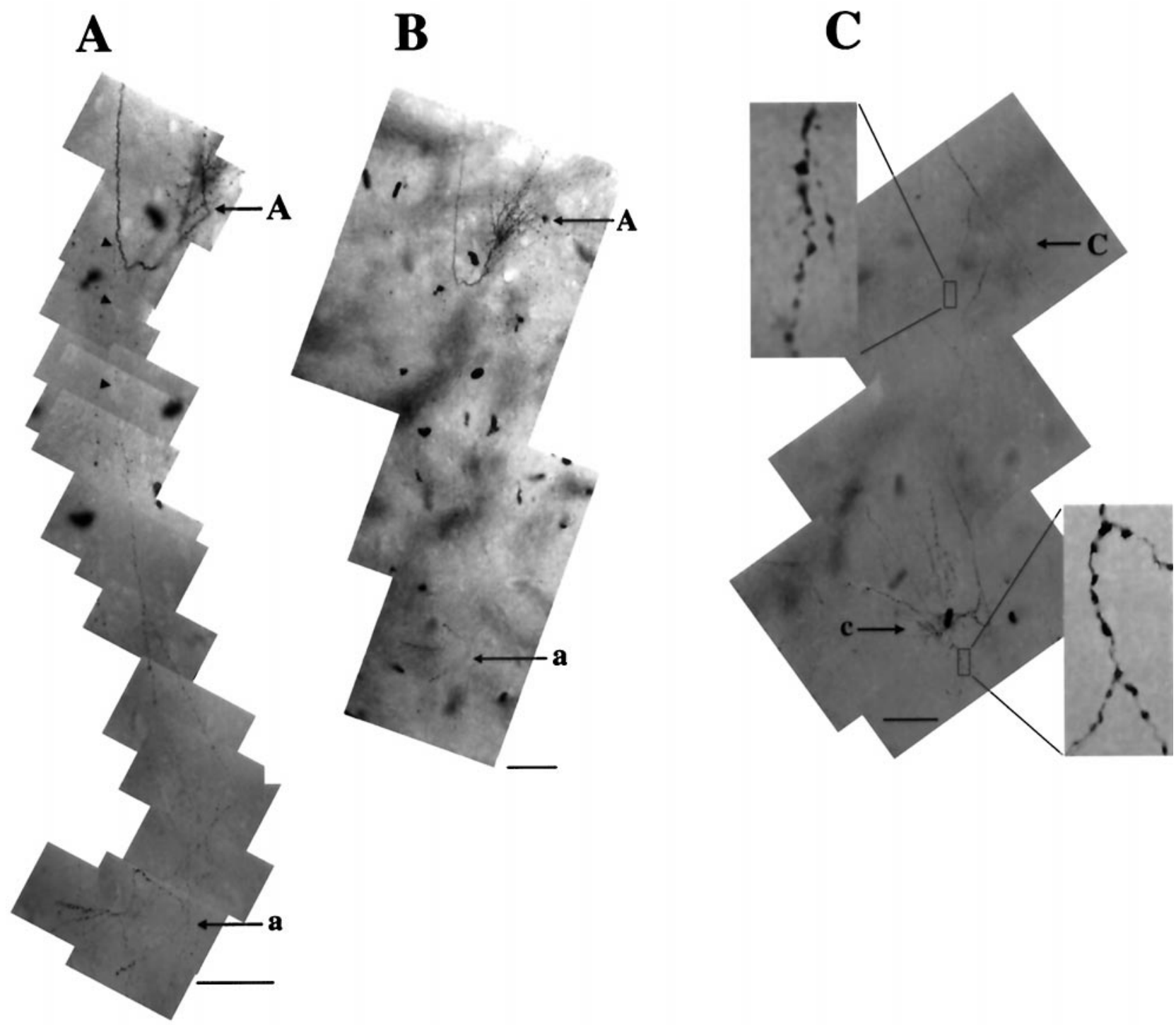

Figure 7. Photomicrographic montages showing HRP labeling in two-headed axons at 5 and 10 weeks PM. $A$, Axon 1 is from an animal at 10 weeks PM. The arbor at old site $a$ and the stem leading to it are much thinner than the arbor at new site $A$. The contrast in this photomicrograph is adjusted to emphasize the connection between two arbors. Only a lightly stained portion of the arbor at $A$ is shown to demonstrate the faintly stained branches at $a$. Arrowheads point to the beginning part of the old arbor. $B$, The same axon is presented to show better the difference in intensity of HRP staining in two arbors, with the whole arbor at site $A$ being shown. The HRP labeling in its arbor at old site $a$ is substantially lighter than that in its arbor at new site $A$. $C$, Axon 3 is from an animal at 5 weeks PM. The HRP labeling in its arbors at both old site $c$ and new site $C$ are similar. Insets are high-magnification views of branches from the two arbors (under a $100 \times$ objective). Scale bar, $50 \mu \mathrm{m}$. Photomicrographs were taken using a $100 \times$ objective in $A$ and a $25 \times$ objective in $B$ and $C$.

Given that activity-independent cues instruct isthmotectal axons to arborize at one location and activity-dependent cues tell the same set of axons to go elsewhere, how do axons respond to these two conflicting forces? We observe axons with two distinct arbors, at locations corresponding to normal and reorganized sites. The existence of two-headed axons in eye-rotated animals at 5 weeks PM suggests that abnormal activity cues trigger isthmotectal axons to form new arbors, although they have already arborized at other locations on the basis of activity-independent cues.

Isthmotectal axons in adults with a rotated eye have only single arbors and these are found at the visuotopically correct locations, so the arbors at the old termination sites in 5-week-old animals are probably resorbed at later stages. As expected, in animals of 10 weeks PM, we observed two two-headed axons that seem to be withdrawing the old arbors. Of the two arbors, one with much lighter HRP staining occupies the old termination sites. Scattered branches or sparse arbors are observed at earlier ages, but the density of staining in them is nevertheless as robust as that in the sibling arbors. We speculate that faint staining reflects a process of atrophy in the old arbors.

Do all the axons shift their arbors in response to eye rotation? One line of evidence that they do not is a study in which enucleation was performed in adult animals with early eye rotation (Brickley et al., 1994). After the contralateral eye was removed, both modified and unmodified ipsilateral maps were recorded in some animals. The growth patterns of isthmotectal axons may be heterogeneous, with some of them being affected by abnormal visual activity and others not. This result could explain why we observed some axons with normal trajectories in eye-rotated animals, although some of these are located in regions, such as the 

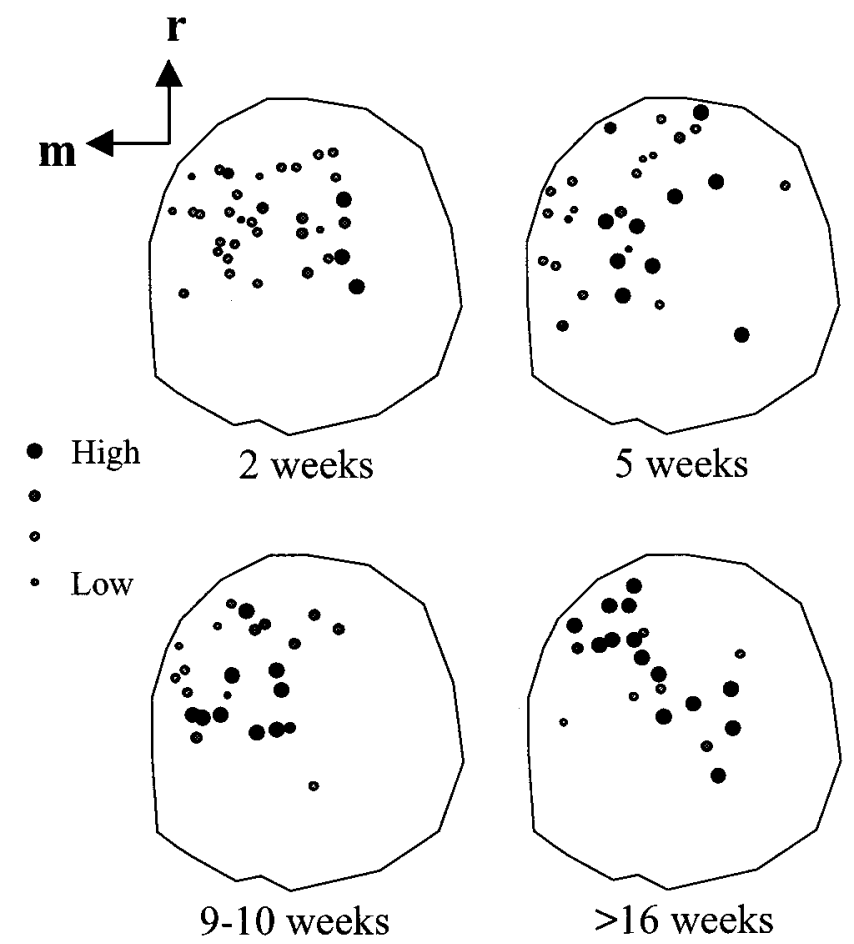

Figure 8. The rearrangement of isthmotectal axons takes place in the sequence of caudolateral to rostromedial. The distributions of the crossing indices of different ranges at 2, 5, 10, and $>16$ weeks PM. Large black circles, dark gray circles, light gray circles, and white circles represent high to low degrees of rearrangement (crossing indices of $<0.1,0.1-0.4,0.4-0.7$, and $0.7-1.0$, respectively).

optical center of rotation at which no changes in trajectories are needed.

Our data suggest that, when isthmotectal axons first grow into the tectum, their guiding factor is chemoaffinity cues (and perhaps correlation of firing patterns of isthmotectal axons with one another). Only during second phase do isthmotectal axons start to respond to binocular visual activity cues. Some threshold density of synaptic connections may be required to trigger this behavior.

This two-stage hypothesis can be tested by taking advantage of the fact that isthmotectal axons mature at different rates. At the time of eye rotation, the majority of isthmotectal axons have arrived in the tectum. However, isthmotectal axons only start to form arbors weeks later (Udin and Fisher, 1985). NI cells projecting to the caudolateral region form arbors earlier than those to the rostromedial border (Grant and Keating, 1989a). If the ability of isthmotectal axons to respond to activity cues is related to their developmental stages, isthmotectal axons should reorganize at the different speeds throughout the tectum. Indeed, our results suggest that reorganization of each isthmotectal axon begins after it has made an arbor in the location defined by chemoaffinity cues. The reorganization starts in the caudolateral region, which contains the oldest arbors, and ends in the rostromedial area, which has the newest arbors. Similar results have been reported with electrophysiological mapping (Grant and Keating, 1992).

Activity can fine-tune the topographic maps that are established by chemoaffinity cues. In Xenopus, rearing animals in the dark during the critical period results in a coarse ipsilateral map that becomes refined after the animals are returned to normal lighting (Grant and Keating, 1989b; Keating et al., 1992). In mammals, blocking binocular visual activity by intraocular infu- sion of TTX during a critical period leads to the formation of abnormally large and diffuse arbors in both LGN and visual cortex (Sretavan and Shatz, 1986; Sretavan et al., 1988; Antonini and Stryker, 1993b). Monocular deprivation during the critical period results in a reduction of axon branches in geniculocortical afferents serving the occluded eye and the expansion of afferents serving the normal eye (Antonini and Stryker, 1993a). In the regeneration of the goldfish retinotectal projection, both strobe light and blocking of activity induces retinal ganglion cells to grow abnormally enlarged arbors (Schmidt and Buzzard, 1990, 1993).

What are the cellular events that are triggered by activity that affect the arborizations of isthmotectal axons? One scenario is that correlated activity between isthmotectal axons and retinotectal axons activates NMDA receptors in postsynaptic tectal cells, stabilizes their dendrites (Cline, 1998; Wu and Cline, 1998), and promotes the release from dendrites of signals that stabilize active terminals (Constantine-Paton and Cline, 1998). Several lines of evidence support the role of NMDA receptors in activitydependent reorganization of isthmotectal axons. During the critical period, NMDA application accelerates the reorganization of isthmotectal axons in response to eye rotation (Bandarchi et al., 1994); conversely, NMDA antagonists block this process (Scherer and Udin, 1989). Isthmotectal axons release acetylcholine rather than glutamate; the ability of ACh to increase glutamate release from retinotectal terminals is likely to increase the impact of retinotectal activity on tectal cells (King and Schmidt, 1991; Titmus et al., 1999).

We propose that retrograde signals promote the growth and stabilization of branches at the site of release, without affecting the total branch number and the length of an axon. This model is supported by the results of studies of retinotectal axons in Xenopus (Rajan et al., 1999) showing that blocking NMDA receptor activity increases the rates of branch retractions and additions in retinotectal axons, but that the branch number and axonal length stay unchanged over a $24 \mathrm{hr}$ period. Studies done on cultured tectal cells also have shown that blocking NMDA receptors increases neurite motility and sprouting (Lin and Constantine-Paton, 1998).

How does activity prompt isthmotectal axons to stay or reorganize? If the chemoaffinity-specified arbor is formed at a site with correlated activity, local release of retrograde signals promotes the growth and stabilization of the arbors. Isthmotectal axons form small branches outside the arbor (Udin, 1989); however, without stabilization signals, they disappear eventually because they are at a competitive disadvantage. If the arbor is first formed in a region without correlated activity, the axon will extend and retract branches outside the arbor at a increasing rate. By trial and error, some branches extend to areas with correlated activity and receive the signals for growth and elaboration, and a new arbor forms. In the meantime, because an axon can only sustain a certain number of branches, the old arbor will lose the competition and retract.

The axons at transitional stages in eye-rotated animals displayed relatively few side branches, which is unexpected if the axons extend branches randomly to search for the locations with correlated activity by trial and error. Our staining method may have failed to catch very transient branches. Alternatively, the searching process may not be completely by chance; perhaps some of the visuotopic organization within the isthmotectal population is preserved during the reorganization process. Connections made by a given isthmotectal axon may help to stabilize branches made by neighboring isthmotectal axons with similar receptive fields.

The two-headed axons call to mind the dual projections in the 
inferior colliculus of barn owls reared with prisms that create a mismatch between visual and auditory tectal maps (Feldman and Knudsen, 1997). In those animals, connections mediating the normal auditory topographic map coexist with connections mediating a map that matches the shifted visual map. In contrast with Xenopus isthmotectal projections, the owls' dual projections persist anatomically into adulthood, with the influence of the normal connections being suppressed by inhibitory interneurons (Zheng and Knudsen, 1999).

In summary, the above results suggest that, in animals with early eye rotation, isthmotectal axons are initially guided by activityindependent cues and establish connections at locations that have been rendered "incongruent" by the eye rotation. These arbors allow the axons to detect the activity mismatch, prompting them to search other tectal areas for correlated activity and to make arbors there; in the meantime, the old, incorrect arbors are withdrawn.

\section{REFERENCES}

Antonini A, Stryker MP (1993a) Rapid remodeling of axonal arbors in the visual cortex. Science 260:1819-1821.

Antonini A, Stryker MP (1993b) Development of individual geniculocortical arbors in cat striate cortex and effects of binocular impulse blockade. J Neurosci 13:3549-3573.

Bandarchi J, Scherer WJ, Udin SB (1994) Acceleration by NMDA treatment of visually induced map reorganization in juvenile Xenopus after larval eye rotation. J Neurobiol 25:451-460.

Brickley SG, Keating MJ, Grant S (1994) Experience-dependent mechanism of binocular map plasticity in Xenopus: incongruent connections are masked by retinal input. Neurosci Lett 182:13-16.

Brickley SG, Dawes EA, Keating MJ, Grant S (1998) Synchronizing retinal activity in both eyes disrupts binocular map development in the optic tectum. J Neurosci 18:1491-1504.

Cline HT (1998) Topographic maps: developing roles of synaptic plasticity. Curr Biol 8:R836-R839.

Cline HT, Constantine-Paton M (1989) NMDA receptor antagonists disrupt the retinotectal topographic map. Neuron 3:413-426.

Constantine-Paton M, Cline HT (1998) LTP and activity-dependent synaptogenesis: the more alike they are, the more different they become. Curr Opin Neurobiol 8:139-148.

Feldman DE, Knudsen EI (1997) An anatomical basis for visual calibration of the auditory space map in the barn owl's midbrain. J Neurosci 17:6820-6837.

Gaze RM, Keating MJ, Östberg A, Chung S-H (1979) The relationship between retinal and tectal growth in larval Xenopus: implications for the development of the retino-tectal projection. J Embryol Exp Morphol 53:103-143.

George SA, Marks WB (1974) Optic nerve terminal arborizations in the frog: shape and orientation inferred from electrophysiological measurements. Exp Neurol 42:467-482.

Glasser S, Ingle D (1978) The nucleus isthmus as a relay station in the ipsilateral visual projection to the frog's optic tectum. Brain Res 159:214-218.

Goodman CS, Shatz CJ (1993) Developmental mechanisms that generate precise patterns of neuronal connectivity. Neuron 10:77-98.

Grant S (1982) The development and modification of binocular neuronal connections in Xenopus laevis. PhD thesis, University of London.

Grant S, Keating MJ (1986) Normal maturation involves systematic changes in binocular visual connections in Xenopus laevis. Nature 322:258-261.

Grant S, Keating MJ (1989a) Changing patterns of binocular visual connections in the intertectal system during development of the frog, Xenopus laevis. I. Normal maturational changes in response to changing binocular geometry. Exp Brain Res 75:99-116.

Grant S, Keating MJ (1989b) Changing patterns of binocular visual connections in the intertectal system during development of the frog, Xenopus laevis. II. Abnormalities following early visual deprivation. Exp Brain Res 75:117-132.

Grant S, Keating MJ (1992) Changing patterns of binocular visual connections in the intertectal system during development of the frog, Xenopus laevis. III. Modifications following early eye rotation. Exp Brain Res 89:383-396.
Gruberg ER, Udin SB (1978) Topographic projections between the nucleus isthmi and the tectum of the frog Rana pipiens. J Comp Neurol 179:487-500.

Katz LC, Shatz CJ (1996) Synaptic activity and the construction of cortical circuits. Science 274:1133-1138.

Keating MJ, Feldman JD (1975) Visual deprivation and intertectal neuronal connexions in Xenopus laevis. Proc R Soc Lond B Biol Sci 191:467-474.

Keating MJ, Grant S (1992) The critical period for experiencedependent plasticity in a system of binocular visual connections in Xenopus laevis: its temporal profile and relation to normal developmental requirement. Eur J Neurosci 4:27-36.

Keating MJ, Grant S, Dawes EA, Nanchahal K (1986) Visual deprivation and the maturation of the retinotectal projection in Xenopus laevis. J Embryol Exp Morphol 91:101-115.

Keating MJ, Dawes EA, Grant S (1992) Plasticity of binocular visual connections in the frog, Xenopus laevis: reversibility of effects of early visual deprivation. Exp Brain Res 90:121-128.

King WM, Schmidt JT (1991) The long latency component of retinotectal transmission: enhancement by stimulation of nucleus isthmi or tectobulbar tract and block by nicotinic cholinergic antagonists. Neurosci 40:701-712.

Lin S, Constantine-Paton M (1998) Suppression of sprouting: an early function of NMDA receptors in the absence of AMPA/Kainate receptor activity. J Neurosci 18:3725-3737.

Nieuwkoop PD, Faber J (1967) A normal table of Xenopus laevis (Daudin). Amsterdam: North Holland.

O'Leary DD, Wilkinson DG (1999) Eph receptors and ephrins in neural development. Curr Opin Neurobiol 9:65-73.

Rajan I, Witte S, Cline HT (1999) NMDA receptor activity stabilizes presynaptic retinotectal axons and postsynaptic optic tectal cell dendrite in vivo. J Neurobiol 38:357-368.

Scherer WJ, Udin SB (1989) $N$-Methyl-D-aspartate antagonists prevent interaction of binocular maps in Xenopus tectum. J Neurosci 9:3837-3843.

Schmidt JT, Buzzard M (1990) Activity-driven sharpening of the regenerating retinotectal projection: effects of blocking or synchronizing activity on the morphology of individual regenerating arbors. J Neurobiol 21:900-917.

Schmidt JT, Buzzard M (1993) Activity-driven sharpening of the retinotectal projection in goldfish: development under stroboscopic illumination prevents sharpening. J Neurobiol 24:384-399.

Schmidt JT, Edwards DL (1983) Activity sharpens the map during the regeneration of the retinotectal projection in goldfish. Brain Res 269:29-39.

Sperry RW (1963) Chemoaffinity in the orderly growth of nerve fiber patterns and connections. Proc Natl Acad Sci USA 50:703-710.

Sretavan DW, Shatz CJ (1986) Prenatal development of retinal ganglion cell axons: segregation into eye-specific layers within the cat's lateral geniculate nucleus. J Neurosci 6:234-251.

Sretavan DW, Shatz CJ, Stryker MP (1988) Modification of retinal ganglion cell axon morphology by prenatal infusion of tetrodotoxin. Nature 336:468-471.

Titmus MJ, Tsai HJ, Lima R, Udin SB (1999) Effects of choline and other nicotinic agonists on the tectum of juvenile and adult Xenopus frogs: a patch-clamp study. Neuroscience 91:753-769.

Udin SB (1983) Abnormal visual input leads to development of abnormal axon trajectories in frogs. Nature 301:336-338.

Udin SB (1989) The development of the nucleus isthmi in Xenopus. II. Branching patterns of contralaterally projecting isthmotectal axons during maturation of binocular maps. Vis Neurosci 2:153-163.

Udin SB, Fawcett JW (1988) Formation of topographic maps. Annu Rev Neurosci 11:289-327.

Udin SB, Fisher MD (1983) Visualization of HRP-filled axons in unsectioned, flattened optic tectum. J Neurosci Methods 9:283-285.

Udin SB, Fisher MD (1985) The development of the nucleus isthmi in Xenopus laevis. I. Cell genesis and formation of connections with the tecta. J Comp Neurol 232:25-35.

Udin SB, Keating MJ (1981) Plasticity in a central nervous pathway in Xenopus: anatomical changes in the isthmotectal projection after larval eye rotation. J Comp Neurol 203:575-594.

Wu GY, Cline HT (1998) Stabilization of dendritic arbor structure in vivo by CaMKII. Science 279:222-226.

Zheng W, Knudsen EI (1999) Functional selection of adaptive auditory space map by GABAA-mediated inhibition. Science 284:962-965. 